Short Communication

\title{
A SURVEY TO ASSESS PATIENT SATISFACTION AFTER RECEIVING COM PLETE DENTURE PROSTHESES IN A.B. SHETTY MEM ORIAL INSTITUTE OF DENTAL SCIENCES
}

\author{
Vinaya S. Bhat ${ }^{1}$, Krishna Prasad D. ${ }^{2} \&$ Prakyath Malli ${ }^{3}$ \\ ${ }^{1}$ Professor, ${ }^{2}$ Professor \& HOD, ${ }^{3}$ P. G. Student, Department of Prosthodontics and Crown \& Bridge \\ A.B. Shetty M emorial Institute of Dental Sciences, Nitte University, Deralakatte, \\ M angalore -575 018, Karnataka, India. \\ Correspondence : \\ Prakyath Malli \\ P.G. Student, Department of Prosthodontics and Crown \& Bridge, A.B. Shetty M emorial Institute of Dental Sciences, \\ Nitte University, Deralakatte, M angalore - 575 018, Karnataka, India. \\ M obile : +91 8095727027 E-mail : Prakyath_m@ hotmail.com
}

\section{Abstract:}

Conventional complete denture therapy is the most extensively used form of treatment for replacement of missing dentition. Patient satisfaction plays a major role in determining the success during treatment procedures. It helps in assessment of certain psychological traits and the impact of complete denture prostheses on daily living. This study was done to evaluate the relationship between patient satisfaction and the newly constructed denture prostheses, as it would indicate the degree of success of the treatment given.

Keywords: Patient Satisfaction, Denture Satisfaction, Psychological Factors

\section{Introduction:}

Conventional complete denture prostheses have been widely used for the replacement of missing dentition. Advancements in complete denture fabrication and techniques have been improved over the years, however little attention has been paid towards the psychological impact of the patient after receiving the prostheses. Psychological factors may play a role and also provide valuable information for the prediction of satisfactory outcome of complete denture treatment. Several other factors like mastication and speech also contribute to the ultimate success of the treatment. This survey was done to investigate if clinical quality of new complete dentures predicts patient satisfaction, to investigate possible relationships between patient and clinical factors and patient satisfaction with new complete dentures.

\begin{tabular}{|c|}
\hline Access this article online \\
\hline Quick Response Code \\
\hline
\end{tabular}

Department of Prosthodontics and Crown and Bridge Implantology, A B Shetty Memorial Institute of Dental Sciences. Patients were recalled after two weeks of receiving the prosthesis.

\section{Inclusion Criteria:}

Patients who received complete denture prostheses from the department recently (within two weeks).

\section{Exclusion Criteria:}

Patients with implant supported complete denture prostheses.

Patients with complete denture prostheses made elsewhere.

Patients wearing complete denture prostheses for more than two weeks.

\section{Methodology :}

The selected patients were made to sit on the dental chair comfortably. After obtaining their written consent to participate in the study, a questionnaire was filled in consultation with the patient. The details regarding the newly constructed prostheses was recorded as it was reported by the patient. The patient was encouraged to 
give frank opinion about his/her new denture and was assured that the identity would be kept confidential. The questions were asked in his/her own mother tongue. Once the questionnaire was completed for 40 patients, they were grouped based on the scale of very happy, happy ,average, not happy, not at all happy for different parameters like i) Retention, ii) aesthetics, iii) speech, iv) mastication, v) finish of the denture, and vi) overall satisfaction for maxillary and mandibular dentures.

\section{Results:}

Among the total population (40) chosen for the study 24 were males and 16 were females.

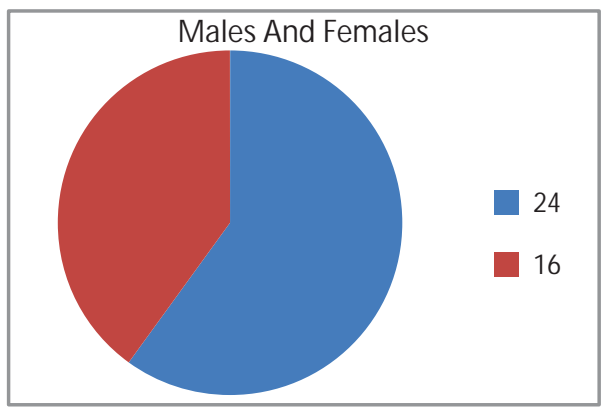

Diagram 1: Gender Grouping Of Population I) RETENTION

A) Patient satisfaction related to fit of the upper denture

22 /40(54\%) Patients were very happy with the fit of upper denture

14/40(21\%) Patients were happy with the fit of upper denture 2/40(9\%) Patients had average satisfaction

1/40(8\%) Patient were not happy with the fit of upper denture $1 / 40(8 \%)$ Patient were not at all happy with the fit of upper denture

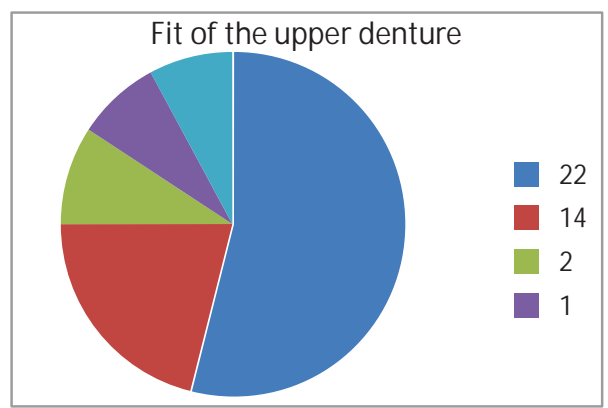

B) Patient satisfaction as related to Fit of the lower denture 9/40(23\%) Patients were very happy with the fit of lower denture

25/40(63\%) Patients were happy with the fit of the lower denture

4/40(10\%) Patients had average satisfaction with the fit of the lower denture

2/40(5\%) Patients were not happy with the fit of lower denture

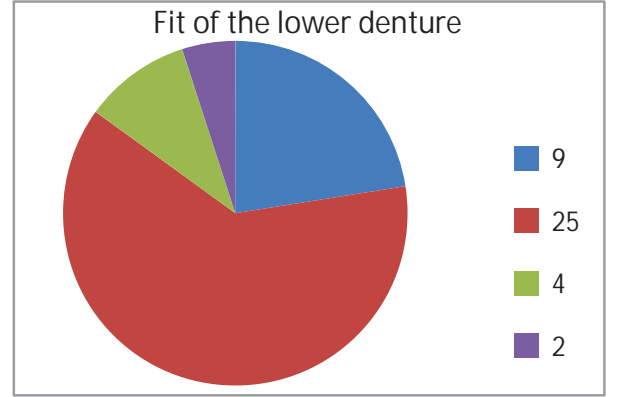

II) AESTHETICS

A) Patient satisfaction as related to Color of the denture. $18 / 40(45 \%)$ Patients were very happy with the color of denture

$17 / 40(43 \%)$ Patients were happy with the color of denture $5 / 40(13 \%)$ Patients had average satisfaction with the color of denture.

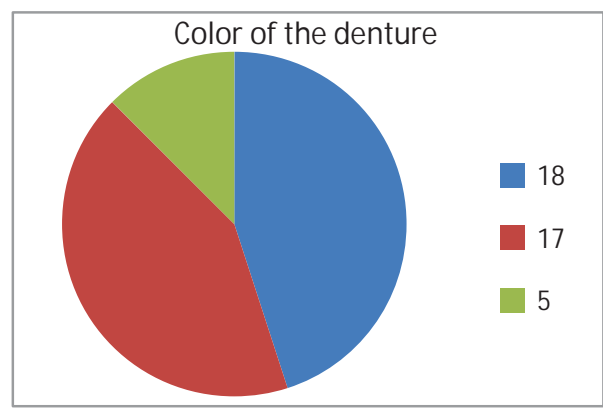

B) Patient satisfaction as related to color of the Teeth 19/40(48\%) Patients were very happy color of the teeth $18 / 40(45 \%)$ Patients were happy with the color of teeth $3 / 40(8 \%)$ Patients had average satisfaction with the color of teeth.

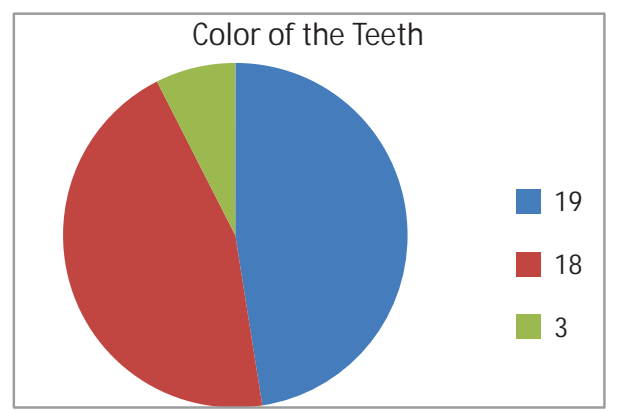

C) Patient satisfaction as related to Appearance of face after receivingthe denture

$21 / 40(53 \%)$ Patients were very happy with the appearance of face

$16 / 40(40 \%)$ Patients were happy with the appearance of face $3 / 40(8 \%)$ Patients had average satisfaction with the appearance of face 


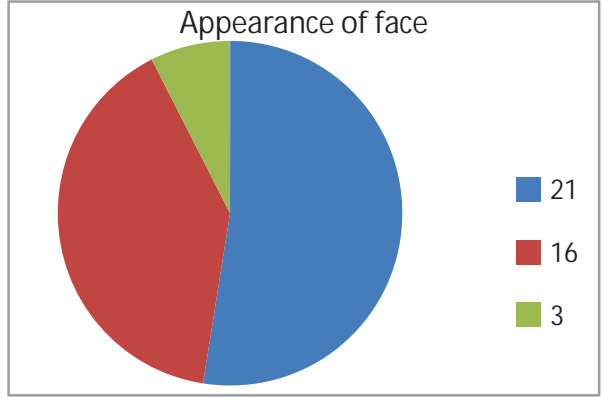

III) Patient satisfaction as related to Speech.

10/40(25\%) Patients were very happy with speech

17/40(43\%) Patients were happy with speech

$13 / 40(33 \%)$ Patients had average satisfaction with speech.

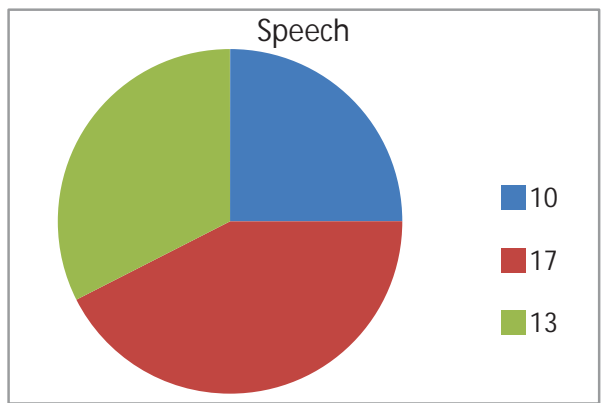

IV) Patient satisfaction as related to Mastication.

9/40 (22\%) Patients were very happy with mastication 16/40(40\%) Patients were happy with mastication

14/40(35\%) Patients had average satisfaction with mastication 1/40(3\%) Patients were not happy with mastication.

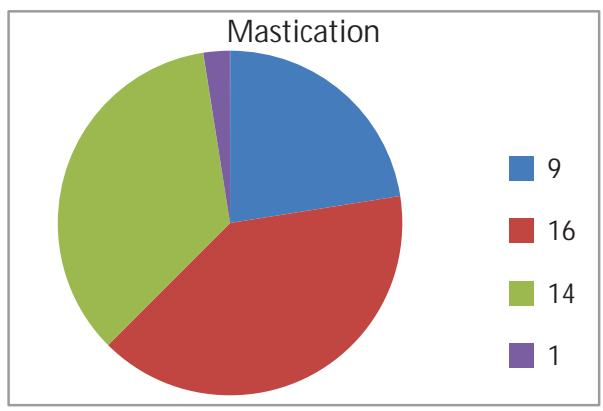

V) Patient satisfaction as related to Smoothness of the denture $17 / 40(43 \%)$ patients were very happy with the smoothness of the denture

$20 / 40(50 \%)$ patients were happy with the smoothness of the denture

$3 / 40(8 \%)$ had average satisfaction with smoothness of the denture

\section{Discussion :}

Patient satisfaction has been the ultimate goal in any dental treatment. In a patient receiving a complete denture prostheses, many factors have a combined role in achieving his/her satisfaction. For an operating dentist efficient mastication, good aesthetics, comfortable speech and

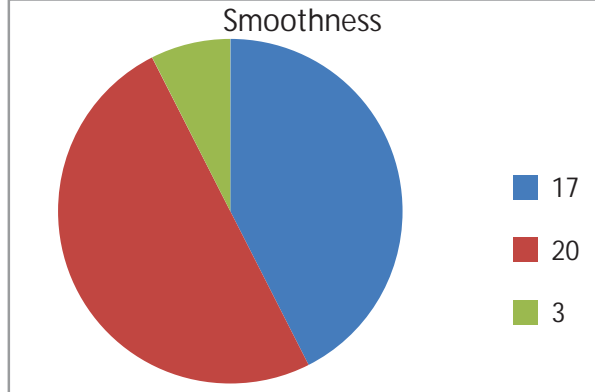

VI) Overall satisfaction

21/40(53\%) Patients were very happy with the denture.

14/40(35\%) Patients were happy with the denture.

4/40(10\%) Patients had average satisfaction with the denture.

1/40 (3\%) Patient was not happy with the denture.

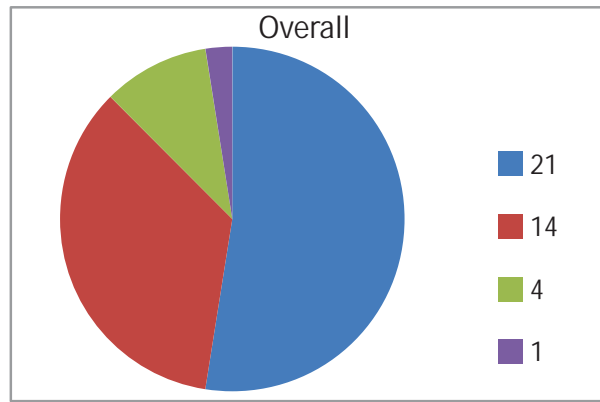

wearing comfort for the patient have been the ultimate concern. To meet both ends of patient dentist relationship and treatment outcome could be achieved by a psychological assessment as related to satisfaction. In a study conducted by Marinus A J, ${ }^{6}$ et al, they evaluated the patient-dentist relationship after the treatment was completed. Patients were asked opinion regarding the treatment and also their attitude and expectation from the new denture were recorded with the help of a questionnaire.

Treatment to be a success, not only operators objectives have to be met with, but also most importantly, the patient has to be satisfied. However, patient's personality also is a related factor in assessing the criteria for his/her satisfaction.

In another study done by Marinus $\mathrm{A},{ }^{5}$ on determinants of dissatisfaction with dentures the results showed that satisfaction with dentures for most patients is individually determined and, for dentist and patient it is often unpredictable. 
Michael Robert Fenlon et al, ${ }^{9}$ stated that Quality of the mandibular residual alveolar ridges, retention and stability of the mandibular dentures, accuracy of reproduction of retruded jaw relationship and patient adaptability were powerful determinants of patients' satisfaction with new complete dentures.

The present survey was conducted in the department at ABSM IDS with 40 patients who had received complete denture prostheses recently. Denture satisfaction was assessed based on retention, aesthetics (color of teeth, denture and appearance), speech, mastication, smoothness and overall satisfaction. Grading scale used was very happy, happy, average, not happy, not at all happy. The following results were obtained $54 \%$ of the patients were very happy with the fit of upper denture only and $23 \%$ of the patients were very happy with the fit of lower denture. This reduction is probably because the amount of retention provided by adhesion is proportionate to the area covered by the denture. Mandibular dentures cover less surface area than maxillary prostheses and therefore are subject to lower magnitude of adhesive and retentive forces. $^{13}$

Color of the denture base and the artificial teeth has been the major factor in achieving satisfactory appearance in denture patients. In our study, about $45 \%$ of the patients were very happy with the color of the denture, $48 \%$ of the patients were very happy with the color of teeth, $53 \%$ of the patients were very happy with the appearance of the face. Ellis s et al ${ }^{1}$, in his pilot study reported that there was increased satisfaction among patients with improved aesthetics. Aesthetics has direct initial impact on patient satisfaction.

Production of sounds with the prosthesis placed on a movable tissue like oral mucosa has always been problematic. The denture prosthesis, however well adapted will undergo small amount of movement when placed on a movable base. Hence, speech with new denture is always not satisfactory, at least during its initial period of its wearing. In our survey only $25 \%$ of patients were comfortable with speech. E Berg ${ }^{11,12}$, also in his assessment of 74 denture patients stated that major prosthodontic problem during period of adaptation was related to speech. However, with the persistent wearing and practice, all patients get accustomed to good speech.

Mastication is another most important main function to be carried out with the dentition. With roots of natural teeth embedded within the bone, this function is carried out effortlessly. However, with the new prosthesis that is just placed in contact with unstable mucosa, it is a herculean task to perform. Patient who is in transition from dentulous to edentulous state finds it difficult to handle the movements of the prostheses on a moving foundation. Edentulous patients are clearly handicapped in masticatory function, and even clinically satisfactory complete dentures are a poor substitute for natural teeth. ${ }^{13}$

In the present survey it was found that only $22 \%$ of patients were happy with mastication. However this factor is tissue dependent and motivational factor by the patient plays a vital role in improving masticatory efficiency.

Smoothness has been associated with comfort of wearinga prostheses. $43 \%$ of the patients were very happy with smoothness of the denture. Hence were comfortable in wearing the prostheses.

Comfort of wearing gives overall satisfaction to the wearer. $53 \%$ patients were very happy with the denture.

\section{Conclusion :}

It has been said that a patient can either make or break a dental practice. During a patient's management, an operator may be satisfied with the quality of work done by $\mathrm{him} /$ her, but it is the amount of patient satisfaction that determines the success of the treatment. Hence assessment of patient satisfaction should be a routine part of any practice after the treatment is complete. This will help in constant improvement in the quality of services provided by healthcare workers. 


\section{References:}

1. Ellis JS, Thomason JM, Mc Andrew R. A pilot study examining the effects of enhanced aesthetics on oral health related quality of life and patient's satisfaction with complete dentures. Eur J Prosthodont Restor Dent, 2010; 18(3):116-22.

2. Ellis JS, Pelekis ND, Thomason JM. Conventional rehabilitation of edentulous patients: the impact on oral health-related quality of life and patient satisfaction. J Prosthodont, 2007; 16(1):37-42.

3. Kelly SA, Hyland RM, Ellis JS, Thomason JM, Moyiniyan PJ. Development of a patient-based questionnaire about emotional and social issues related to eating with dentures. J Dent, 2012;40(8):67885.

4. Frank RP, Milogrom P, Leroux BG, Hawkins NR. Treatment outcomes with mandibular removable partial dentures: A population based study of patient outcomes.J Prosthodont, 1998; 80(1):36-45.

5. Marinus AJ. Determinants of dissatisfaction with dentures: A multiple regression analysis. The Journal of Prosthetic Dentistry, 1990; 64(5):569-572.

6. Marinus AJ. The influence of psychologic factors on patient satisfaction with complete dentures. The Journal of Prosthetic Dentistry, 1990; 63(5):545-548.

7) Boerrigter EM, Geertman ME, Van Oort RP, Bouma J, Raghoebar GM, van Waas AJ, van't Hof M A, Boering G, Kalk W. Patient Satisfaction with implant retained mandibular over dentures. A comparision with new complete dentures not retained by implants, A multicentre randomized clinical trial. British Journal of Oral and Maxillofacia Surgery, 1995;33(5):282-288

8. Boerrigter EM, Stegenga B, Raghoebar GM, Boering G. Patient satisfaction and chewing ability with implant-retained mandibular overdentures: A comparison with new complete dentures with or without preprosthetic surgery. Journal of Oral and Maxillofacia Surgery, 1995; 53(10):1167-1173.

9. Fenlon MR, Sherriff M . An investigation of factors influencing patients' satisfaction with new complete dentures using structural equation modeling. Journal of Dentistry, 2008; 36(6):427-434

10. Fenlon M R, Sherriff M . Investigation of new complete denture quality and patients' satisfaction with and use of dentures after two years. Journal of Dentistry, 2004; 32(4):327-333.

11. Berg $E$. The influence of some anamnestic, demographic, and clinical variables on patient acceptance of new complete dentures. Acta Odontol Scandinavica, 1984; 42(2):119-127.

12. Garret NR, Kapur KK, Perez P. Effects of improvements of poorly fitting dentures and new dentures on patient satisfaction. Journal of Dentistry, 1996; 76(4): 403-413.

13. Zarb GA, Bolender CL. Prosthodontic Treatment for Edentulous Patients.12 Ed. M osby; 2009:10,438. 